\title{
IDENTIDAD, EDUCACIÓN, GÉNERO Y NACIÓN. A GALIZA IMAXINADA A TRAVÉS DE LA PRENSA GALLEGA DE LA EMIGRACIÓN $(1915-1936)^{\alpha}$
}

\author{
Identity, education, gender and nation. A Galiza imaxinada \\ through the Galician emigration press (1915-1936)
}

\section{María Eugenia Bolaño Amigo ${ }^{\beta}$}

Fecha de recepción: 05/01/2020 • Fecha de aceptación: 31/01/2020

Resumen. Este trabajo se aproxima a las representaciones de la Galiza imaxinada que, mediante textos e imágenes relacionados con la educación y la infancia, se trazan a través de la prensa gallega de la emigración. Con esta finalidad, se parte del análisis de contenido de una muestra que comprende la totalidad de números publicados entre los años 1915 y 1936 por las revistas Céltiga (Buenos Aires, Argentina) y Eco de Galicia (La Habana, Cuba) atendiendo, en particular, a las representaciones identitarias que traspasan las nociones de género, clase social y nación.

Palabras clave: identidad; educación; género; nación; Galiza.

Abstract. This work examines the representations of the Galiza imaxinada - Galicia imagined - that, through texts and images related to education and

\footnotetext{
${ }^{\alpha}$ Partimos aquí de los avances propiciados por el proceso de realización de la Tesis Doctoral que llevó por título: Representacións textuais e icónicas da infancia, da primeira adolescencia e da súa educación en revistas culturais e prensa gráfica galega (Galiza, Bos Aires e A Habana) e madrileña: 1915-1936. Entre o Naturalismo, a Socialización e a Distinción Social, dirigida por el Dr. Antón Costa Rico (Universidade de Santiago de Compostela) y la Dra. María del Mar del Pozo Andrés (Universidad de Alcalá de Henares), a través de la que pudimos analizar las diversas representaciones de la infancia y de su educación que se proyectan en órganos que, además de suscitar estados de opinión, generaron representaciones de presente y de futuro social, permitiéndonos indagar en el mejor conocimiento de los proyectos sociales y culturales de la época.

El texto original de este trabajo está escrito en lengua gallega: Identidade, educación, xénero e nación. A Galiza imaxinada a través da prensa galega da emigración (1915-1936). A lo largo del mismo se mantienen las citas literales en su lengua original e, igualmente, se respeta la ortografía de origen.

B Departamento de Pedagoxía e Didáctica, Facultade de Ciencias da Educación, Universidade de Santiago de Compostela. Rúa Prof. Vicente Fráiz Andón s/n. Campus Vida, 15782. Santiago de Compostela. España. mariaeugenia.bolano@usc.es (D) https://orcid.org/0000-0002-2436-7144
} 
childhood, are portrayed by the press produced by Galician emigrants. For this purpose, we analyze the content of a sample that includes all the numbers published between 1915 and 1936 of Céltiga (Buenos Aires, Argentina) and Eco de Galicia (La Habana, Cuba), magazines that specifically address the representations of identity that go beyond the notions of gender, social class and nation.

Keywords: identity; education; gender; nation; Galiza.

\section{INTRODUCCIÓN}

A través de este artículo pretendemos, como objetivo fundamental, aproximarnos a las representaciones de la Galiza imaxinada ${ }^{1}$ que, a través de la prensa gallega de la emigración -y particularmente mediante los textos e imágenes ligados a la educación y a la infancia-, se esbozan y perfilan en torno a la cuestión identitaria, penetrando en las nociones de género, clase social y nación. ${ }^{2}$

Este trabajo emerge tras el proceso de realización de la Tesis Doctoral que llevó por título Representacións textuais e icónicas da infancia, da primeira adolescencia e da súa educación en revistas culturais e prensa gráfica galega (Galiza, Bos Aires e A Habana) e madrileña: 1915-1936. Entre o Naturalismo, a Socialización e a Distinción Social, dirigida por el Dr. Antón Costa Rico (Universidade de Santiago de Compostela) y la Dra. María del Mar del Pozo Andrés (Universidad de Alcalá de Henares), a través de la que pudimos analizar las diversas representaciones de la

\footnotetext{
${ }^{1}$ Esta conceptualización ha sido utilizada en la historiografía gallega contemporánea (concretamente por parte de destacados historiadores como Ramón Villares o Xosé M. Núñez Seixas) para hacer alusión, en particular, al diálogo entre los retratos reales e idealizados de Galiza, en tanto que ósmosis que acaba por conjugarse en los imaginarios que, también, se trasladan a través del discurso. Concretamente, bajo la denominación Galiza imaxinada se desarrolló, entre los años 2015 (Galiza) y 2016 (Argentina), la exposición comisariada por Chus Martínez Domínguez y organizada por el Consello da Cultura Galega, que tuvo por objeto fundamental retratar la Galiza de la emigración real e idealizada, visibilizando también las influencias del fenómeno migratorio en la creación de las imágenes de Galiza a partir del siglo XIX. Aún, esta noción nos remite al discurso Alba de gloria que, el 25 de julio de 1948 en Buenos Aires, pronuncia Castelao: «É moito mellor evocar algo irreal, algo puramente imaxinario, algo que co seu simbolismo nos deixe ver o pasado para proveito do futuro, como unha boa experiencia».

2 Teniendo bien presentes las alertas de María del Mar del Pozo Andrés, Currículum e identidad nacional. Regeneracionismos, nacionalismos y escuela pública (1890-1939) (Madrid: Biblioteca Nueva, 2000), y de Roy Lowe, «Education and national identity», History of Education 28, no.3 (1999): 231, al destacar la pertinencia y relevancia del estudio de las relaciones entre identidad nacional y educación para la historiografía educativa.
} 
infancia y de su educación que se proyectan en órganos que, además de suscitar estados de opinión, generaron representaciones de presente y de futuro social, permitiéndonos indagar en el mejor conocimiento de los proyectos sociales y culturales de la época. La Tesis a la que aludimos posibilitó la apertura de nuevos interrogantes e inquietudes, sólo parcialmente hilvanados en algún caso, que enhebran ahora nuevos proyectos de investigación, entre los que se sitúa la temática abordada en este texto.

Atendiendo a las pretensiones enunciadas, el estudio parte de la revisión y análisis cualitativo de contenido de los 182 números editados entre 1924 y 1932 por Céltiga (que constituyen una totalidad de 6.382 páginas), y de los 223 números publicados entre 1917 y 1936 por Eco de Galicia (8.431 páginas en total). Esta amplia muestra nos permite indagar en las proyecciones de los segmentos sociales que reflejan su imaginario social en estos medios, aproximándonos al mejor conocimiento de la Galiza imaxinada y, por lo tanto, de las realidades vividas y deseadas para el porvenir gallego, representadas también en las visiones de la infancia y de su educación que se trasladan.

En relación a fuentes primarias manejadas, conviene destacar que Céltiga resulta, entre todas las publicaciones gallegas que se divulgaron por territorios argentinos y cubanos durante el primer tercio del siglo $\mathrm{XX}$, la más destacada por su cuidada calidad y reconocida importancia en el desarrollo del galeguismo y del entonces incipiente nacionalismo gallego; y la publicación Eco de Galicia, por haber gozado de una notable estabilidad y perdurabilidad en el tiempo. Ambas constituyen cabeceras de singular relevancia debido a su gran acogida y repercusión entre las comunidades emigradas e, igualmente, resultan representativas de los contextos americanos configurados como núcleos de mayor presencia de gallegos y gallegas.

\section{LA PRENSA GALLEGA DE LA EMIGRACIÓN EN LA RE-CONSTRUCCIÓN DEL IMAGINARIO GALLEGO}

Advertía Hobsbawm en su prefacio al libro The invention of tradition de 1983, que estudiar los procesos de construcción de tradiciones, símbolos e identidades es el modo de rescatar «síntomas importantes» de problemáticas que, con los datos y fuentes convencionales, no logran 
comprenderse. Retomando recientemente esta cuestión, señala Villares que «las tradiciones, que por veces se confunden con las costumbres y con la herencia, no importan tanto en sí mismas, sino en sus significados: cómo legitiman los poderes y cómo socializan valores y sentimientos especialmente "líquidos" para la mirada del historiador». ${ }^{3}$ De ahí la importancia de estudiar los relatos elaborados por las elites contemporáneas sobre hitos y hechos de la historia y su valor para construir y/o «imaginar» una cultura y una nación; relatos que, también, se hacen eco, re-elaboran y trasladan a través de la prensa y, particularmente en el caso gallego de inicios del siglo XX, de la prensa de la emigración.

La prensa gráfica y cultural del primer tercio del siglo XX editada en el contexto de la emigración gallega a ultramar, resultó crucial para la expansión de tendencias ideológicas y culturales de aquel entonces, jugando un papel decisivo en la conformación de las mentalidades de las elites gallegas. Más allá de establecer un canal propio de comunicación entre la comunidad migrante, que pudiese atender a sus necesidades (recogiendo informaciones de los lugares de origen, o actuando como nexo de comunicación y «achega entre as dúas Galizas», tal como destacó Neira Vilas), ${ }^{4}$ las revistas constituyeron ágoras desde las que expresar lazos de unión entre la colectividad emigrada. Así, los órganos de prensa publicados por los gallegos y gallegas en América suscitaron estados de opinión, generaron representaciones de presente y de futuro social y propiciaron un mejor conocimiento de los proyectos sociales y culturales de la época, transmitiendo una determinada visión de la realidad existente y deseada, atendiendo, igualmente, a las preocupaciones del momento. En este sentido, y en la línea en que ha trabajado Taboada González, «a través desta fonte de primeira orde para os historiadores preténdese chegar non só aos grupos que crean e monopolizan a prensa -e para os que estes van dirixidos fundamentalmente-, senón tentar sobrepasar este límite e poder chegar a ter unha visión o máis socialmente englobadora posíbel». ${ }^{5}$

Los órganos de difusión publicados en la diáspora ofrecen elementos a sus lectores que propician un contacto directo con sus raíces y

\footnotetext{
${ }^{3}$ Ramón Villares, Identidade e afectos patrios (Vigo: Galaxia, 2017), 10.

${ }^{4}$ Xosé Neira Vilas, A prensa galega en Cuba (Sada: Ediciós do Castro, 1985), 7.

${ }^{5}$ Sabela Taboada González, E fíxose a nación. Os albores da nación española na prensa galega (18081814) (A Coruña: Deputación provincial da Coruña, 2011), 20.
} 
orígenes, bien sea a través de sus contenidos, del idioma en que se escriben -con menor protagonismo en los casos que analizamos- o de otros elementos de identificación; de este modo, «é común a representação de assuntos e informações ligados à preservação e manutenção das identidades cultural (hábitos, costumes, tradições, língua etc.), nacional, étnica e social do imigrante». ${ }^{6}$

Tomando como referencia los trabajos del historiador Núñez Seixas, conviene considerar, cuando menos, tres variables a la hora de indagar en el desarrollo y representación de las identidades colectivas, en las imágenes y sentimientos identitarios de lo "propio» y de lo «ajeno», si nos referimos a un colectivo emigrante, como es el caso de los gallegos y gallegas que publicaban Céltiga, desde Buenos Aires, y Eco de Galicia, desde La Habana:

En primeiro lugar, a identidade colectiva que os emigrantes dunha determinada orixe xeográfica común transportan e transplantan con eles, pois o emigrante non se converte nun desarraizado, como presupuxo máis dun autor seguindo o trazo de O. Handlin en 1951, senón que recrea una identidade étnica de orixe (...). En segundo lugar, a preservación, modificación ou desaparición da súa identidade colectiva no seo de, ou fronte á sociedade receptora, que segundo o contexto de oportunidades devirá en asimilación ou integración sociocultural e política. En terceiro lugar, a súa acomodación, competición, redefinición identitaria ou fusión con outras colectividades de inmigrantes foráneos residentes na mesma sociedade de acollida, e cos que se entra en contacto. ${ }^{7}$

Aún, las reflexiones de González-Millán, ${ }^{8}$ de Queizán ${ }^{9}$ y de Miguélez-Carballeira, ${ }^{10}$ entre otras, nos brindan claves para incorporar en

\footnotetext{
${ }^{6}$ Camila Escudero, «A Imprensa Imigrante: Uma Fonte de Representaçao de Identidades Reais e Simbólicas», Investigaçao Qualitativa 1, no.1 (2016): 29.

7 Xosé Manoel Núñez Seixas, O inmigrante imaxinario (Santiago de Compostela: Universidade de Santiago de Compostela, 2002), 19.

${ }^{8}$ Xoán González Millán, Resistencia cultural e diferencia histórica: A experiencia da subalternidade (Santiago de Compostela: Sotelo Blanco, 2000).

${ }_{9}$ María Xosé Queizán, Opening address at launch of the issue 'O verbo patriarcal'. Festa da palabra silenciada (Vigo: Escola de Artes e Oficios, 2009).

${ }^{10}$ Helena Miguélez-Carballeira, Galiza, um povo sentimental? Género, política e cultura no imaginário nacional galego (Santiago de Compostela: Associaçom Galega da Língua, 2014).
} 
nuestro análisis de las representaciones teniendo presentes las nociones de género y de subalternidad en el discurso que remite a las identidades, atendiendo a las aproximaciones ofrecidas por parte de los estudios poscoloniales.

Partiendo de estos preceptos, efectuamos a continuación una aproximación a los órganos de prensa analizados para profundizar después en los aspectos ligados a las identidades, a las infancias y a su educación en estos medios.

\section{La revista Céltiga}

La revista ilustrada Céltiga comienza a publicarse en Buenos Aires (Argentina) el 30 de septiembre de 1924, fundada por Domingo Rial Seijo, antiguo dirigente de la Casa de Galicia, y por el reconocido dibujante Ramón Peña. La publicación, tal como expresaba su subtítulo inicial (Revista Gallega de arte, crítica, literatura y actualidades: Publicación quincenal editada por la Editorial Céltiga), abordaba cuestiones relacionadas con el «arte, crítica, literatura y actualidades». De su dirección literaria se ocuparon personalidades destacadas como Adolfo Vázquez Gómez o, con posterioridad, Eduardo Blanco Amor, Ramón Suárez Picallo y Eliseo Pulpeiro.

Céltiga se configuró como «voceiro de intercambio e de encontro da intelectualidade galega residente na Arxentina da emigración, actuando con vocación de ponte entre Galiza e Hispanoamérica». ${ }^{11}$ Sus páginas, orientadas por un ideario galeguista (acentuado con la aparición de la sección Idearium galeguista), trataban de favorecer el mutuo conocimiento e intercambio entre la Galiza territorial, la Galiza emigrante y Argentina, procurando la difusión de ideas y problemáticas derivadas de la situación vivida en ambas márgenes del océano. La revista acude a una permanente exaltación de la tierra y de la galeguidade (no exenta de representaciones estereotipadas, tal como nos permite visibilizar

\footnotetext{
11 María Eugenia Bolaño Amigo, «Representacións textuais e icónicas da infancia, da primeira adolescencia e da súa educación en revistas culturais e en prensa gráfica galega (Galiza, Bos Aires e A Habana) e madrileña: 1915-1936. Entre o Naturalismo, a Socialización e a Distinción Social» (Tese de Doutoramento, Universidade de Santiago de Compostela, 2017), 779.
} 
Miguélez-Carballeira), ${ }^{12}$ por lo que puede afirmarse que constituyó un órgano que «desempeñou un papel crucial no proceso de afirmación e desenvolvemento do galeguismo entre as comunidades galegas de América». ${ }^{13}$ Así, en la propia publicación se bosquejan los deseos para el porvenir de la revista:

que debe ser galega, patriótica, democrática e progresista, e que, partindo do galego e en concordancia coas ideas e cos sentimentos da época; lembrando as tradicións do pasado, pero sen estancarse no presente, e enfrontando con decisión o porvir, no que xa se deixan entrever claras auroras: aurora do rexurdimento de Galicia, aurora no novo camiñar do mundo cara anchos horizontes de espiritualidade e de vida digna e libre. ${ }^{14}$

Los propósitos de la publicación serían, según Núñez Seixas:15

a) modernizar e enriquecer a cultura galega mediante a súa expansión e apertura ao diálogo coas culturas iberoamericanas; b) defender os postulados do galeguismo de maneira pragmática e moderada, abríndose ademais á posibilidade de servir de voceiro oficioso aos nacionalistas de Galicia, acollendo as tendencias máis republicanas dentro do mesmo; e c) crear un produto editorial de calidade, tanto estética como de contidos, que contribuíse a aumentar o prestixio da colectividade inmigrante ante a sociedade receptora.

En ella pueden leerse crónicas y artículos con información sobre las sociedades gallegas de emigrados, aspecto al que se destinan especialmente las secciones Motivos de Crónica o El momento de Galicia, que analizan la actualidad gallega y de la colectividad emigrante. Se aprecian también variados textos de creación literaria (relatos) y artículos de asuntos culturales; se observan fotografías de paisajes y de ciudades

\footnotetext{
12 En su obra Galiza, um povo sentimental? Género, política e cultura no imaginário nacional galego, que publica en el año 2014 (Santiago de Compostela, Associaçom Galega da Língua).

${ }_{13}$ Sylvia Pulpeiro e Pablo Rodríguez (Eds.), Eliseo Pulpeiro. As letras galegas entre dúas ribeiras (Ribadeo e Río da Prata) (Santiago de Compostela: Consello da Cultura Galega, 2016), 9.

${ }_{14}$ Pulpeiro e Rodríguez, Eliseo Pulpeiro, 82.

${ }_{15}$ Xosé Manoel Núñez Seixas, O soño da Galiza ideal. Estudos sobre exiliados e emigrantes galegos (Vigo: Galaxia, 2016), 212.
} 
gallegas, así como un amplio y variado material de ilustración integrado por viñetas, dibujos, caricaturas, grabados y fotografías. En prácticamente todos los números de Céltiga hay lugar para: las notas biográficas, los relatos literarios, el teatro, el abordaje de motivos y de figuras argentinas, así como las secciones destinadas al humor, entre otras cuestiones que suelen estar presentes. Constituyen temas recurrentes el referido a la infancia (en Páginas infantiles, o a través de las fotografías en Pequeños tiranos), a la educación (destacando las páginas denominadas Apuntes Pedagógicos), a la mujer (Labores femeninas), a la información de las asociaciones gallegas de la emigración (Por nuestras sociedades), entre otras.

El marco ideológico en el que Céltiga se posicionó a lo largo de su trayectoria, varió con ciertos matices de intensidad, si bien caminó siempre en las dimensiones del ideario republicano y del galeguismo nacionalista. ${ }^{16}$ Atendiendo a la cuestión lingüística, Céltiga fue una revista bilingüe con mayor presencia del español aunque, en años posteriores y con la incorporación de nuevos colaboradores, la presencia de la lengua gallega irá en aumento. Las aportaciones de Evaristo Correa Calderón, Portela Pérez, Vicente Risco, Ramón Suárez Picallo, Antonio Noriega Varela, Luis Porteiro, Leandro Carré o Lugrís Freire, caminaron en este sentido.

Con el paso del tiempo, Céltiga estableció relaciones con los galeguistas de Europa, con la Irmandade Nazonalista Galega de Vicente Risco y con la Irmandade da Fala da Coruña; además, comenzó a tomar partido en la política sudamericana, mostrando simpatía por la revolución mexicana y criticando la política estadounidense en América Latina. En todo caso, y atendiendo a las consideraciones de Núñez Seixas, "a moderación da mensaxe e a calidade da publicación conseguiron que Céltiga obtivese un grande éxito e unha notábel difusión entre os galegos de

\footnotetext{
${ }^{16}$ A este respecto indica Núñez Seixas que «nas súas páxinas se expresaban de maneira sutil contidos nacionalistas, xa desde o primeiro editorial» (Núñez Seixas, O soño da Galiza ideal, 212). Podemos apreciar un reflejo de estas afirmaciones en la propia publicación: "Céltiga cumplirá así una elevada función patriótica, la más grande tal vez. Mantener vivo y latente el vínculo al "terruño"; afianzar, estrechar los vínculos afectivos de los descendientes de Breogán con el solar de la raza, es asegurar, indubitablemente, el interés y cooperación de los mismos para todos los problemas de la región» (sic., «Nuestro Programa», Céltiga 1(1924): 3.
} 
Arxentina, Uruguay e Chile». ${ }^{17}$ El propio Blanco Amor remite, en el año 1928, al «triunfo» del «buen sentido gallego y (...) capacidad diplomática (...), dentro de todos los lectores conscientes de Céltiga, en su organismo mental, estas ideas son hoy calorías de intenso galleguismo, de consciente intuición prenacionalista». ${ }^{18}$

Las ilustraciones de la revista incidieron en que esta fuese apreciada debido a su calidad estética y artística, además de por la relevancia intelectual de sus colaboradores. ${ }^{19}$ Son representativos los reportajes fotográficos sobre los paisajes y las principales ciudades gallegas, así como las fotografías correspondientes a eventos y acontecimientos sociales importantes tanto en las ciudades gallegas de la emigración como en las de la Galiza territorial. El material ilustrado que aparece es cuidado, múltiple y heterogéneo. La publicidad es muy abundante y la mayor parte de los anuncios pertenecen a establecimientos comerciales, compañías de navegación, productos de consumo cotidiano, compañías de seguros, bancos, entre otros.

La revista es publicada quincenalmente, y su número de páginas oscila entre las 32 o 40, si bien estas aumentan de modo notable en los números extraordinarios. Céltiga dejó de editarse a partir del mes de julio de 1932 y, en la actualidad, la totalidad de los 182 números publicados se encuentran públicamente accesibles a través de la página web institucional del Consello da Cultura Galega. ${ }^{20}$

\section{Identidades, educación e infancia en Céltiga}

La infancia y su educación aparecen representadas en Céltiga a través de un amplio conjunto de textos, fotografías, viñetas, dibujos, ilustraciones y grabados. Mediante la publicidad e, igualmente, en las

\footnotetext{
17 Núñez Seixas, O soño da Galiza ideal, 213.

18 Blanco Amor, Céltiga 73 (1928):3.

19 Entre los que podemos destacar, entre otros, a Ramón Cabanillas, Amando Carballo, Xavier Bóveda, Alfonso Castelao, Castro Seijo, Antón Alonso Ríos, Avelino Díaz, Wenceslao Fernández Flórez, Manuel Leiras Pulpeiro, Herminia Fariña, Manuel Lugrís Freire, Victoriano Taibo, Francisca Herrera Garrido o Xosé Lesta Meis.

${ }^{20}$ El enlace web que da acceso a la publicación es: www.consellodacultura.gal
} 
crónicas y noticias, niñas y niños (estos últimos con mayor presencia) ${ }^{21}$ son retratadas/os desde un mundo adulto que muestra interés por otorgarles un rol protagónico; cuestión que puede apreciarse en buena medida en las secciones Páginas infantiles o Pequeños tiranos. Niños y niñas adquieren en la revista ilustrada una relevante presencia, a pesar de que cuantitativamente ocupen un espacio reducido -correspondiente al $5,53 \%$ de las páginas analizadas-. En este sentido, valoramos que existe en Céltiga el interés de dotar de visibilidad a la infancia y a su educación debido, en parte, a las implicaciones que esto puede suponer para el aún entonces incipiente proyecto político nacionalista gallego que (con diversos matices) subyace a las páginas de la revista.

Así, es reiterativa la idea de infancia como «semente» del porvenir de la «nazón galega», erigiéndose como "xermolo do futuro» sobre el que depositar «as espranzas do porvir» [sic.]; de modo que los deseos de cambio sociopolítico tienden a confiarse a una educación que parte del conocimiento de lo propio, ligada al contorno rural de origen:

Queremos que cada niño gallego conozca el suelo que pisa y las gentes que lo habitan; de donde viene su raza y adonde va; la ciencia sencilla que le haga hermano atento de las plantas familiares y amigo de las bestias humildes que ayudan a ganar el pan; $\mathrm{y}$ atento observador del mar, que es fuente de tesoros y hervidero de bellezas.

Hacerle consciente y sensible de los encantos y de la riqueza de su tierra. Romper hasta donde sea posible la rutina salvaje fomentada por una pedagogía filistea que obliga al niño gallego a saber quién fué el bruto de D. Enrique de Trastamara, y no se le

\footnotetext{
${ }^{21}$ La presencia de representaciones masculinas es substancialmente superior a las correspondientes con el género femenino y, en este caso, aludimos no sólo a la prevalencia de la figura del hombre frente a la mujer, sino también a la mayor presencia de metáforas que emplean la masculinidad asociándola a rangos de superioridad, frente a la feminización de aquellos aspectos a los que se confieren roles de subordinación. A estas expresiones del patriarcado, se añaden cuestiones de clase social y de territorio, sobreponiendo, en todo caso, la tríada «masculino- clase alta- urbano (vida pública)» a la conjugación «femenino- clase baja- rural (vida privada)» que, precisamente, es con la que tiende a personificarse Galiza. Compartimos, pues, los argumentos de Miguélez-Carballeira cuando afirma la prevalencia de una «estrategia por la cual se feminiza aquello que se pretende desvalorizar» (Miguélez-Carballeira, Galiza, um povo sentimental, 20); afirmaciones que entroncan con las tesis de Janet Sorensen al reconocer la centralidad de las cuestiones de género en los juegos de poder imperialistas, así como con los trabajos de Carmen Blanco o de María Xosé Queizán, entre otras.
} 
nombra al padre Feijóo, que le llena la cabeza de monos sabios de Samaniego y se le deja ignorar a Curros y a Lamas; que le habla de unos caballeros barbudos que mataban moros y no se le dice quien labró el pórtico de Compostela [sic.].22

Los niños y las niñas aparecen retratados/as en Céltiga como «suprema espranza da Patria galega [sic.]», por lo que su educación es fundamental y la escuela juega un papel crucial para el "progreso» deseado. Tanto a través de imágenes como de textos se aprecian escenas de tipo costumbrista que representan la vida en el rural de la tierra de origen, trasladando cierta nostalgia. Podemos señalar que estas representaciones de la infancia y de su educación en Céltiga entroncan, cuando menos parcialmente, con las reflejadas a través del pequeño libro editado por vez primera en 1925, Os nenos, ${ }^{23}$ de Filgueira Valverde.

Son múltiples los textos que desarrollan críticas de la escuela presente (que podemos comprender en sus dimensiones "prescrita, real y vivida», si atendemos a las nociones referidas por Viñao Frago) ${ }^{24}$ acompañadas de los esbozos de una escuela que, más que deseada es soñada y reivindicada como necesidad para el "progreso social» y el «desarrollo cultural». ${ }^{25}$ En las páginas de la publicación ilustrada se pone en valor la importancia de una «educación moral» que procure «despertar la humanidad» de las personas; no obstante, a medida que los números avanzan, se percibe una mayor focalización en la idea de educación para el futuro de la «Suprema Patria Galega».

Existe en Céltiga una sección específicamente destinada a las cuestiones pedagógicas que responde a la denominación Apuntes Pedagóxicos;

22 Discurso de Eduardo Blanco Amor, «leido en el Festival Pro Libro Escolar Gallego», por Eduardo Blanco Amor, Céltiga 45 (1926): 8.

${ }^{23}$ El libro aparece, además, reiteradamente en la publicidad de la revista desde el año de su publicación, y a él se alude explícitamente en algunos textos, porque se asume que representa a «os verdadeiros nenos galegos», que «se ríen de los papás que no dejan a sus niños hablar en gallego, ni siquiera decir 'fiuncho'» (sic.; A propósito de "Os nenos» de Filgueira Valverde, por Critias. Céltiga 33 (1926): 22.

${ }^{24}$ Antonio Viñao Frago, «Escolarización, edificios y espacios escolares», CEE Participación Educativa 7 (2008): 16-27.

${ }^{25}$ No nos centraremos aquí en los aspectos específicamente relacionados con las representaciones de la escuela y de los espacios escolares, que abordamos ya en trabajos previos como: María Eugenia Bolaño Amigo, «Representaciones de los espacios escolares a través de la prensa gallega de la emigración: Eco de Galicia (1917-1936) y Céltiga (1924-1932)»,en Espacios y patrimonio histórico-educativo, coords. Paulí Dávila y Luis M. Naya (Donostia: EREIN, 2016), 775-794. 
aunque también, a través de las Páginas Infantiles, se abordan aspectos ligados a la educación. En ambas secciones se asume que la educación moral es fundamental, al sobreentender que «la moral es la base de la familia, la unión de la sociedad, el bienestar de los pueblos. La educación moral concierne a la voluntad y a la forma de someterla a las reglas del deber. La supremacía de esta potencia entre todas las humanas manifiesta la de esta educación sobre la del cuerpo y la del entendimiento».26

Se espera del proceso educativo que «enseñe» al niño a "ser bueno», desarrollando en él ciertas potencialidades estimables para cuando sea adulto como: «actividad, franqueza y sinceridad, discreción, benevolencia, urbanidad y obediencia. Y debemos hacer lo posible por combatir el egoísmo del que emanan la sensualidad, el interés y la avaricia, la envidia y la pereza; y en el niño, la presunción, el orgullo, vanidad, cólera, dureza y crueldad, obstinación y terquedad y la mentira», ${ }^{27}$ y que tanto la escuela como el maestro potencien en el las cualidades necesarias para favorecer el «progreso» de Galiza.

Con todo, son muchos los silencios que se trasladan a través de las páginas de la publicación con respecto a las representaciones que nos ocupan aquí; y puede apreciarse que, con el paso de los años de edición de la revista, este vacío aumenta constatablemente. ${ }^{28}$

\section{La revista Eco de Galicia}

Eco de Galicia comienza a editarse en el año 1917 en La Habana (Cuba) fundada por Manuel Fernández Doallo, quien ejerció durante más tiempo como su director. Al frente de la publicación estuvieron, durante períodos de tiempo más breves, Manuel Gondell Linares y Mercedes Vieito Bouza, en la última etapa de la revista, manteniendo el perfil establecido por quien la iniciara. La cabecera se constituye

\footnotetext{
26 José Guixé ,«Apuntes Pedagógicos», Céltiga 13 (1925):32.

27 José Guixé ,«Apuntes Pedagógicos», Céltiga 13 (1925):32.

${ }_{28}$ Es entre 1924 (inicio de la publicación) y 1927 cuando se aprecia un mayor número de imágenes y textos destinados a la representación de la infancia y de su educación, aspecto que parece estar ligado a la presencia de la figura del progresista y masón Adolfo Vázquez Gómez en la Redacción de Céltiga, después ausente del proyecto. Se observa también que el notable descenso de representaciones se ve acentuado en 1932, en buena medida justificado por la desaparición de la revista en ese mismo año.
} 
como revista «ilustrada e de información rexional» que atiende, desde el otro margen del océano, a las cuestiones sociales y culturales ligadas a Galiza.

Junto con las publicaciones Galicia y Cultura Gallega, fue paulatinamente configurándose como una de las revistas gallegas de Cuba más relevantes del siglo XX, manteniendo su acogida y aceptación a lo largo del tiempo. Durante su trayectoria -que se extiende hasta el año 1936recibió como subtítulos, entre otros: Revista gráfica y de información de la colonia gallega en Cuba (entre los números 71 e 95), o Revista gráfica y de información regional (a partir del número 111).

Su periodicidad resultó muy irregular, variando como publicación semanal, quincenal y mensual a lo largo del tiempo; de igual modo, su número de páginas también fue muy cambiante, entre las 24 y las 54 . En sus páginas predomina la lengua española, mientras que el gallego es utilizado de modo anecdótico en poemas y relatos.

La revista, editada por la Empresa de Publicidad Galiciana, puede encuadrarse en un marco ideológico galeguista regionalista. En sus páginas se atiende a temáticas muy variadas, fundamentalmente cuestiones históricas, geográficas, económicas, folclóricas, filológicas, literarias y artísticas; además, en ella se incluyen: artículos informativos sobre las instituciones gallegas, noticias sobre la sociedad y la cultura cubana y gallega; biografías; bibliografías; trabajos de tipo histórico, geográfico, económico y cultural; y una Páxina Nazonalista, en la que publicaron, entre otros: Vicente Risco, Manuel Banet Fontenla, Xohán Vicente Viqueira, Luis Peña Novo, Isolino Pérez, Basilio Álvarez o Vicente Rebollar. Son varias las secciones que presentaron continuidad en el devenir de la revista, como el Correo de Galicia, centrada en noticias ligadas al panorama gallego; la sección Vida de la Colonia, que incluye novedades sobre diversas actividades llevadas a cabo por parte de las Sociedades (aludiendo principalmente a aspectos lúdicos, entre los que destacan las fiestas y comidas); las páginas de Marcando orientacións -especie de editorial anónimo-; o bien la sección De mi tierra, escrita por Xosé Lesta Meis y que incorpora artículos varios.

Impresa en papel semicromado con un formato de $27 \times 20 \mathrm{~cm}$., la publicación que nos ocupa presenta múltiples y variadas ilustraciones; 
son abundantes las fotografías evocadoras de paisajes gallegos, calles, ciudades, monumentos, puertos y personajes destacados del panorama político y cultural. La publicidad que presenta es muy abundante, sobre todo concentrada en las primeras y últimas páginas de la revista. Los anuncios que predominan son de tipo comercial, de bancos, de aseguradoras, de compañías de navegación e institucionales.

Entre las autoras y autores más relevantes que aparecen en Eco de Galicia destacamos textos, en lengua española, entre otros, de: Concepción Arenal, Jesús Bal y Gay, Roberto Blanco Torres, Xavier Bóveda, Julio Camba, Manuel Murguía o Jaime Solá; en lengua gallega, aparecen trabajos en verso de Álvarez Limeses, Armada Teixeiro, Blanco Amor, Herminia Fariña, Francisca Herrera, Lamas Carvajal, Leiras Pulpeiro, Benito Losada, Lugrís Freire, Eduardo Pondal, Antonio Prieto, Victoriano Taibo, o López Abrente. Por otra parte, en prosa destacan artículos en gallego de Julio Camba, Rafael Dieste, Xosé Filgueira Valverde, Antonio Fraguas, Manuel Portela Valladares, Antón Vilar Ponte; y narraciones de Xosé Arias e Portela, Leandro Carré, Domingo Quiroga, Roxelio Riveiro, Castelao y Avelino Rodríguez Elías, entre otro

\section{Identidades, educación e infancia en Eco de Galicia}

La infancia y su educación suelen aparecer representadas en las abundantes páginas de Eco de Galicia a través de artículos, cuentos, poesías, crónicas, noticias informativas, ilustraciones y viñetas cómicas; pero su voz procede siempre de la persona adulta. ${ }^{29}$ Un adulto que observa la infancia desde la nostalgia (a través del recuerdo de vivencias propias de la edad infantil), desde el parentesco y la vinculación familiar (fundamentalmente apelando al vínculo materno-filial); y/o desde la proyección a la deseable sociedad futura. Así, la infancia no sólo aparece retratada o relatada como sujeto infantil, sino también como recuerdo y como proyecto de futura persona adulta en la que se confían esperanzas para caminar hacia un porvenir mejor.

\footnotetext{
29 Tanto a través de las imágenes como de los textos, los sujetos infantiles representados suelen ser niños; las niñas en la revista aparecen representadas en menor medida y asumiendo roles de mayor dependencia y sumisión a las personas adultas.
} 
Tras el análisis cualitativo de contenido de los números de la revista gallega de Cuba, detectamos que las imágenes predominantes que giran en torno a la infancia en este medio son aquellas que conciben a los niños y, en menor medida, a las niñas, como seres inocentes y dependientes, susceptibles de protección y de corrección; como anhelo y mitificación anclados en la memoria de un pasado feliz (idílico e idealizado, en el lugar de origen); así como sujetos en proceso de "perfeccionamiento» $\mathrm{y}$ «modelado» de cara al futuro estimado. Todas estas representaciones se encuentran atravesadas por nociones de identidad nacional, de género y de clase social. Así, las representaciones de la infancia y de su educación ocupan un notable lugar en Eco de Galicia, si bien su presencia en las páginas de la publicación se restringe al 5\% de la totalidad de imágenes y textos extraídos. ${ }^{30}$

La cuestión de la emigración aparece reiteradamente en las páginas de la revista abordada como una problemática social a combatir, fundamentalmente debido a las consecuencias que para el futuro de la colectividad gallega pueden derivarse de la diáspora. Lo expresa así el cronista, inicialmente anarquista, Julio Camba en un artículo de la publicación: «La emigración es un bien, y esto es lo malo. También es un bien salir de presidio; pero sería mucho mejor no haber entrado en él». ${ }^{31}$ En este sentido, la realidad de los niños y niñas que se ven abocados a vivir la emigración (bien sea en primera o en tercera persona, pues en muchas ocasiones padecían la emigración de sus familiares más próximos) es tratada con sensibilidad y preocupación, profundizando en la pérdida que supone para la «patria galega» el hecho de favorecer la emigración a América. Desde el semanario se hace, pues, un llamamiento principalmente a las madres, a las familias y al «pobo galego» en general, para luchar por la protección de esos «seres débiles». ${ }^{32}$ De modo genérico, podemos afirmar que todos los textos que aluden a la cuestión migratoria en Eco de Galicia

\footnotetext{
${ }_{30}$ En atención a la variabilidad de la presencia de las representaciones que estudiamos con respecto a los diversos años en los que se publicó Eco de Galicia, destaca el lugar que estas ocupan, principalmente, en el año 1918, decreciendo luego (con ciertas variaciones) con el devenir del tiempo. Se observa cierto despunte de las representaciones estudiadas entre los años 1922 y 1924, si bien mucho menor que en el segundo año de la publicación.

31 Julio Camba, Eco de Galicia 115 (1920):14.

32 Mercedes Vieito Bouza, Eco de Galicia 45 (1918):3l.
} 
son presentados de forma emotiva, con pretensión de despertar la sensibilidad del lector.

La educación y la escuela son percibidas como aspectos fundamentales para combatir el éxodo en Eco de Galicia (al brindar la «instrucción» necesaria para evitar que los niños gallegos emigren) y se erigen en sus páginas tal que elementos necesarios para diseñar el porvenir que procura el colectivo social. De este modo, se retrata a la escuela como "la salvación de una Galicia sumida en el analfabetismo».33 Se valora, además, que la escuela es "patriótica y esencial» por lo que requiere «atención preferente por parte de los Gobiernos ya que es, sin duda, la Institución más importante y de más influencia en el orden social de los pueblos».34 Bajo estos preceptos, los espacios escolares adquieren una singular notoriedad en la revista.

\section{CONCLUSIONES}

La prensa elaborada en la diáspora gallega configura un espacio físico y simbólico capaz de albergar, perpetuar y transmitir, por medio de los registros escrito y fotográfico, todo ese sistema de representaciones del migrante que resulta de especial interés al tomar en consideración la importancia del fenómeno migratorio para la Historia contemporánea de Galiza.

Los textos e imágenes que analizamos a través de la prensa y que atienden a la infancia y a su educación, trasladan nociones de género, de clase social y de nación que inciden en la construcción de la Galiza imaxinada. Entre las representaciones analizadas observamos cómo la propia imagen de Galiza e incluso la conceptualización de Patria galega tiende a personificarse como mujer-niña, rural ${ }^{35}$ y de clase social baja (subsumiendo, por lo tanto, a un doble proceso de feminización e infantilización que se conjuga con su estereotipación bajo un modelo determinado de clase social y de contexto); e, igualmente, cómo se depositan

\footnotetext{
33 José Pacín, «La Escuela como salvación de Galicia», Eco de Galicia 178 (1922):12.

${ }^{34}$ Eco de Galicia, 116 (1920): 10.

35 Valoramos de interés recordar que en este tiempo prevalece, también en la prensa que analizamos, una idea de "progreso» y de «modernización» que se construye mayoritariamente mirando cara las urbes, concibiendo así despreciativamente el rural en tanto que signo de "atraso» y "pobreza».
} 
en la infancia (representada mayoritariamente bajo los valores de la inocencia y de la dependencia) las expectativas de desarrollo futuro de Galiza; o incluso cómo se mira cara esa misma infancia con nostalgia y con deseo de protección (poniendo énfasis en el tiempo pasado).

Si interpretamos estas representaciones bajo la luz de la crítica poscolonial, ${ }^{36}$ apreciamos cómo se trazan, en conjunto, diversos tópicos que inciden en la construcción de una imagen subalternada e inmovilista que entronca con el tropo del «sentimentalismo gallego» en torno al que reflexiona Miguélez -Carballeira con respecto a la literatura gallega y que cobraría también sentido en el caso de la prensa analizada. En esta línea, asumimos que los tópicos que apreciamos se diseñan y configuran interseccionalmente, ${ }^{37}$ de modo que las diversas relaciones de poder y opresiones (de género, de clase social o de identidad nacional, entre otras) acaban por retroalimentarse y construirse simbióticamente.

Así, encontramos en la prensa gallega de la emigración de inicios del siglo XX un abanico de representaciones que conjugan modelos pedagógicos y de infancia con representaciones identitarias nacionales, de género y de clase social, construyendo una retórica que semeja traspasar no sólo el tejido de la prensa analizada, sino la propia historia política y cultural, trasladando una imagen de Galiza como niña que necesita ser cuidada y protegida, pero que no tiene voz propia; e igualmente, construyendo modelos de educación y de infancias gallegas subordinados. Conviene detenerse en estas representaciones para poder «lavrar» ${ }^{38} \mathrm{el}$

\footnotetext{
${ }_{36}$ Fundamentalmente tomando en consideración el concepto de orientalismo desarrollado por Edward Said (en sus obras Cultura e imperialismo y Orientalismo), según el cual «el otro» (el que se quiere colonizar) es pretendidamente «reducido» al ser representado a través de una constante retórica que minimiza su entidad y valor cultural y político, al tiempo que legitima su sometimiento y las acciones imperialistas que inciden en esta cuestión; o, aún, la noción de ambivalencia que, entre otras, teoriza Homi Bhabha (en la obra The location of culture), al afirmar que los procesos de estereotipación colonial superan el binarismo desde el momento en el que la propia cultura «colonizada» o subordinada/subalternada aprende a desarrollarse bajo la retórica creada para la perpetuación de su propio sometimiento por parte de las elites.

${ }^{37}$ Apelamos con esta referencia a la conceptualización de interseccionalidad desarrollada desde las teorías feministas por Kimberlé Crenshaw a partir de 1989.

${ }^{38}$ Esta noción que aquí retomamos es empleada por Villares para invocar la idea de «lavrar»acuñada por Paz Andrade en su libro de ensayos Galiza lavra a súa imagen (1985), «non só para aproveitar a forza desta metáfora, senón tamén para asentar a idea de que "lavrar" o pasado significa estar disposto a revisalo criticamente» (Villares, Identidade, 17).
} 
pasado, de modo que podamos mirar también críticamente nuestro presente para transformarlo.

\section{Nota sobre la autora}

María Eugenia Bolaño Amigo es Doctora en Educación por la Universidade de Santiago de Compostela, titulada en el Máster en Investigación, Diversidad Cultural y Desarrollo Comunitario, Licenciada en Pedagogía y titulada en Música por el Conservatorio Superior de Música de Vigo. Actualmente ejerce profesionalmente como docente en la Cátedra de Clarinete del Conservatorio Superior de Música da Coruña y mantiene su vinculación investigadora con el Grupo de Investigación en Pedagogía Social y Educación Ambiental (SEPA-interea) de la Universidade de Santiago de Compostela. Forma parte del Movimiento de Renovación Pedagógica Nova Escola Galega y es directora de la Revista Galega de Educación. Sus principales líneas de investigación giran en torno a la historia de la educación contemporánea.

\section{REFERENCIAS}

Bolaño Amigo, María Eugenia. «Representaciones de los espacios escolares a través de la prensa gallega de la emigración: Eco de Galicia (1917-1936) y Céltiga (1924-1932)». En Espacios y patrimonio histórico-educativo, coordinado por Paulí Dávila y Luis M. Naya, 775-794. Donostia: EREIN, 2016.

Bolaño Amigo, María Eugenia. «Representacións textuais e icónicas da infancia, da primeira adolescencia e da súa educación en revistas culturais e en prensa gráfica galega (Galiza, Bos Aires e A Habana) e madrileña: 19151936. Entre o Naturalismo, a Socialización e a Distinción Social». PhD diss., Universidade de Santiago de Compostela, 2017.

Escudero, Camila. «A Imprensa Imigrante: Uma Fonte de Representaçao de Identidades Reais e Simbólicas». Investigaçao Qualitativa 1, no. 1 (2016): 29.

González Millán, Xoan. Resistencia cultural e diferencia histórica: A experiencia da subalternidade. Santiago de Compostela: Sotelo Blanco, 2000.

Lowe, Roy. «Education and national identity». History of Education 28, no. 3 (1999): 231-233. 
Miguélez-Carballeira, Helena. Galiza, um povo sentimental? Género, política e cultura no imaginário nacional galego. Santiago de Compostela: Associaçom Galega da Língua, 2014.

Neira Vilas, Xosé. A prensa galega en Cuba. Sada: Ediciós do Castro, 1985.

Núñez Seixas, Xosé Manoel. O inmigrante imaxinario. Santiago de Compostela: Universidade de Santiago de Compostela, 2002.

Núñez Seixas, Xosé Manoel. O soño da Galiza ideal. Estudos sobre exiliados e emigrantes galegos. Vigo: Galaxia, 2016.

Pozo Andrés, María del Mar. Currículum e identidad nacional. Regeneracionismos, nacionalismos y escuela pública (1890-1939). Madrid: Biblioteca Nueva, 2000.

Pulpeiro, Sylvia y Pablo Rodríguez (Eds.). Eliseo Pulpeiro. As letras galegas entre dúas ribeiras (Ribadeo e Río da Prata). Santiago de Compostela: Consello da Cultura Galega, 2016.

Queizán, María Xosé. Opening address at launch of the issue 'O verbo patriarcal'. Festa da palabra silenciada. Vigo: Escola de Artes e Oficios, 2009.

Taboada González, Sabela. E fíxose a nación. Os albores da nación española na prensa galega (1808-1814). A Coruña: Deputación provincial da Coruña, 2011.

Villares, Ramón. Identidade e afectos patrios. Vigo: Galaxia, 2017.

Viñao Frago, Antonio. «Escolarización, edificios y espacios escolares». CEE Participación Educativa 7 (2008): 16-27. 